\title{
Taming of wild Rattus norvegicus by lesions of the mesencephalic central gray
}

\author{
D. C. BLANCHARD, G. WILLIAMS, E. M. C. LEE, and R. J. BLANCHARD \\ Békésy Laboratory of Neurobiology, University of Hawaii, Honolulu, Hawaii 96822
}

\begin{abstract}
Wild-trapped Rattus norvegicus show a consistent pattern of fear and defensive behavior to nonpainful stimuli such as an approaching experimenter, an anesthetized conspecific, or tactile stimulation of the back and vibrassae, as well as to painful stimuli. This reactivity to a range of stimuli, and the different behaviors by which such fear or defensiveness may be expressed, including flight, freezing, vocalization, the jump-attack, and specific biting patterns, make wild rats very appropriate subjects for the analysis of brain mechanisms underlying fear. Lesions of the mesencephalic central gray dramatically lowered these defensive reactions to both painful and nonpainful threat stimuli, reducing or eliminating each of the defensive reactions measured. The subjects showed no evidence of significant motor impairment or disturbance of primary sensory mechanisms. Because these experimental lesions involved considerable damage to the superior colliculi, a second study used wild rats with damage only to the colliculi. These animals displayed some deficits in visually guided behavior and in reactivity to certain tactile stimuli, but most of their fear reactions were intact. These findings suggest that the mesencephalic central gray, traditionally regarded as involved in reactivity to pain, may be one component of a mechanism underlying fear and defensive behaviors to nonpainful as well as noxious stimuli.
\end{abstract}

The mesencephalic central gray has been frequently linked to the processing of nocioceptive information. Stimulation of numerous central gray loci evokes fear and painful sensations in man (Nashold, Wilson, \& Slaughter, 1969) and flight and pain reactions in both cats (Baxter, 1968) and rats (Valenstein, 1965; Sandner, Schmitt, \& Karli, 1979). After damage to the central gray, reductions in defensive behaviors have been obtained in rats (Liebman, Mayer, \& Liebeskind, 1970) and in cats (Skultety, 1958), and pain-induced fighting (Edwards \& Adams, 1974) and flight and escape in rats (Halpern, 1968) also have declined.

Although much of this material suggests a specific link between central gray mechanisms and reactivity to pain, Adams (1979) has suggested that this region is involved with the motivational or associational aspects of defense against threat stimuli. The present study was therefore designed to evaluate the effects of lesions of the dorsal central gray on fear in wild Rattus norvegicus. Because of their intense fear response to humans and to strange conspecifics, which does not depend on the use of pain, wild rats were selected as subjects instead of the more commonly used laboratory strains.

\section{EXPERIMENT 1}

In the first experiment, female $R$. norvegicus with lesions in the midbrain central gray or operated con-

This work was supported in part by NIMH Grant MH29163. Reprint requests may be sent to: R. J. Blanchard, 2430 Campus Road, Honolulu, Hawaii 96822. trols were tested for fear behaviors in response to a variety of threatening, but nonpainful, stimuli or to stimuli associated with pain.

\section{Method}

\section{Subjects}

The subjects were 21 wild female Rattus norvegicus that weighed from 125 to $225 \mathrm{~g}$ at the time of surgery. These rats had been trapped in the cane fields near Hilo, Hawaii, 2 to 6 months before testing. They were housed individually with free access to food and water. The experimental group, which received lesions in the dorsal periaqueductal gray, consisted of 15 animals. The operated control group consisted of 6 animals.

\section{Procedure}

All animals were anesthetized with intraperitoneal injection of sodium pentobarbital $(25 \mathrm{mg} / \mathrm{kg})$ during surgery. The operations were done in a stereotaxic instrument. A stainless steel insect pin, insulated except for the tip, was used to deliver anodal lesioning current. For the central gray group, bilateral lesions $(2 \mathrm{~mA}, 10 \mathrm{sec})$ were made in an area just ventral to the superior colliculus, at $-5.5 \mathrm{~mm}$ posterior to bregma, $M L \pm .7$, and $5.0 \mathrm{~mm}$ below the dura. This site was selected on the basis of pilot studies indicating that behavioral effects could be obtained here without significant sensory or motor damage. Control animals had the electrode lowered to the dorsal border of the central gray and withdrawn without passage of current.

The first set of experimental procedures was run 3 days after surgery and repeated $\mathbf{4 0}$ days postoperatively. These same tests, without the circular runway procedures, were also run 10 and 20 days postoperatively. The shock-elicited defense procedure was run once, at 22 days after surgery, and the defensive attack test was run 28 days postoperatively. This schedule was necessary in order to separate sessions involving pain from sessions involving painless elicitation of fear and defensive behavior.

Activity and flight testing. All subjects were individually placed in a $10 \times 1.5 \mathrm{~m}$ runway that was partitioned in the middle and rounded at the ends so as to leave $.75 \mathrm{~m}$ on all sides. The runway 
floor was marked at 1-m intervals. The subjects were monitored during a 5-min period for line crossing and for circling or other motor dysfunction. At the end of the 5-min period, the experimenter entered the runway and approached the rat at a rate of $.5 \mathrm{~m} / \mathrm{sec}$, stopping when the rat moved more than $.5 \mathrm{~m}$ away in response to this approach. The distance between the experimenter and the subject, when movement occurred, and the distance traveled during the subject's movement were recorded. The experimenter first made five approaches, with a 30-sec interval between approaches. The experimenter then approached the subject at a rate of $1.0 \mathrm{~m} / \mathrm{sec}$ and continued the approach until (1) the subject moved $40 \mathrm{~m}$, (2) the subject was contacted three times in succession, or (3) the subject direct a jump-attack at the experimenter.

Dorsal contact. Subjects were placed individually in an opentop aluminum barrel $(50 \mathrm{~cm}$ in diameter and $120 \mathrm{~cm}$ high) and then tapped lightly on the back with a wooden dowel $(8 \mathrm{~mm}$ in diameter and $50 \mathrm{~cm}$ long). A standard tapping procedure was used in which the end of the dowel was held $2 \mathrm{~cm}$ above the midback. The dowel was then tapped quickly and lightly on the midback. Each trial consisted of three taps. The response of the animal to these taps was scored as: (1) Startle 1-a flinch reaction of the tapped surface only; (2) Startle 2-a flinch of the entire animal; (3) Jump 1-a rapid movement in which two of the animal's paws leave the floor; (4) Jump 2-rapid movement in which all four of the animal's paws leave the floor; and (5) Jump 3 -rapid movement in which the animal jumps $10 \mathrm{~cm}$ or higher. A weighted startle score was obtained by scoring Startle 1 as 1 , up through Jump 3 as 5 , and summing all scores for each animal over the $\mathbf{1 0}$ trials. Reaction to hand clap was similarly scored.

Vibrissae stimulation. Subjects in the barrel had their vibrissae stimulated with a circular brush, $2.5 \mathrm{~cm}$ in diameter, affixed perpendicularly to a 1-m-long wooden dowel. On each stroke, the brush was drawn upward, making extensive contact with the vibrissae but not the snout. The number of strokes needed to make the subject assume the boxing posture or elicit a jumpattack (up to a maximum of 5 ) were measured.

Anesthetized conspecific. A terminally anesthetized female rat was held midventrally at ground level and moved head first toward the subject in the barrel at a constant rate of $5 \mathrm{~cm} / \mathrm{sec}$. Three presentations were made. Boxing, biting, vocalization, and jumpattacks toward the anesthetized target were recorded.

Reactions to handling. The subjects in the barrel were approached by the experimenter with a gloved hand at ground level. To pick them up, the experimenter slid his gloved hand under the animal's body. Response measures included vocalization, biting, and success of the pickup. These scores were summed, with 0 being assigned for a pickup without vocalization or biting and a 3 being assigned when, because of biting and struggling, a pickup was not accomplished.

Shock threshold. This procedure was run in a $24.5 \times 25.5 \mathrm{~cm}$ wooden box with a grid floor and a front panel of Plexiglas, as described in Blanchard, Blanchard, and Takahashi (1978). The subjects were placed in the box individually, and shock thresholds were obtained by determination of the shock intensity that produced a jump on $50 \%$ of its presentations. These shock presentations were $.5 \mathrm{sec}$ in length, and were given in an ascending series.

Shock-elicited defense. The subjects were paired with a $400-\mathrm{g}$ female Wistar rat in the shockbox and monitored for $20 \mathrm{sec}$ for boxing, vocalization, and jump-attacks. They were then given 5 footshocks (.5 sec in duration, $1.5 \mathrm{~mA}$ in intensity), with a 10-sec intershock interval, and were monitored for the same set of behaviors. This was followed by 1 to 20 footshocks at the same intensity but with a 2-sec intershock interval. The series of shocks was terminated when the subject had assumed a boxing posture or when $\mathbf{2 0}$ shocks had been given. The number of shocks to box and the duration of boxing were recorded.

Defensive attack behavior. The subjects were allowed to crawl into a $23.5-\mathrm{cm}$ length of $5.6-\mathrm{cm}$-diam tubing and were confined by a backup bar. Their tails were taped to a rod protruding from the back opening of the tube. A heavily anesthetized female Wistar back opening of the tube. A heavily anesthetized female Wistar rat was used as a target stimulus. The snout of the target was presented $1 \mathrm{~cm}$ under the subject's snout for $2 \mathrm{sec}$. Number of bites to the target's snout and vocalizations were counted. Five presentations were made with a 10 -sec interval and without shock. Tailshock (.1 sec in duration, $5 \mathrm{~mA}$ in intensity) was given during the final 10 presentations of the bite target.

\section{Results}

\section{Histological Results}

Data from two experimental rats were discarded because of unilateral damage, or involvement of the vestibular nucleus, which resulted in gross motor impairment. Maximal and minimal lesions for the remaining 13 rats are shown in Figure 1. Damage was restricted to the posterior portions of the central gray. There was considerable variability in the dorsalventral extent of the lesion, with the least ventral damage extending to the level of the aqueduct and the most ventral damage extending to the level of the dorsal raphe. Two animals had slight raphe damage without motor dysfunctions. All animals had varying degrees of lateral tegmental and superior colliculus damage.

\section{Activity and Flight Testing}

Table 1 presents activity and avoidance in the rectangular runway for Day 3 and Day $\mathbf{4 0}$ after surgery.

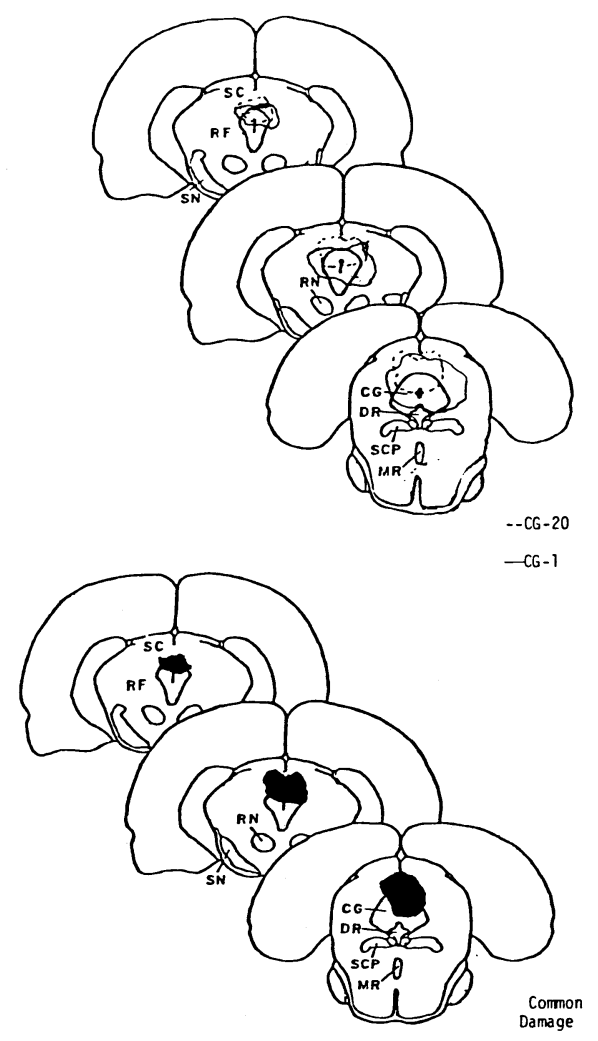

Figure 1. Animals with maximal and minimal extent of lesions and area of common damage for the $\mathbf{1 3}$ experimental animals of Experiment 1. 
Table 1

Activity and Flight in a Circular Runway for Rats With Central Gray Damage and Operated Controls

\begin{tabular}{|c|c|c|c|c|}
\hline \multirow{2}{*}{$\begin{array}{l}\text { Response } \\
\text { Measure }\end{array}$} & \multicolumn{2}{|c|}{ Group C } & \multicolumn{2}{|c|}{ Central Gray Group } \\
\hline & Day 3 & Day 40 & Day 3 & Day 40 \\
\hline Lines crossed in $5 \mathrm{~min}$ & 63.1 & 28.1 & 61.8 & 32.5 \\
\hline Percent of trials on which avoidance occurred & 93.4 & 83.3 & 3.3 & 4.8 \\
\hline Distance eliciting flight (in meters) & 2.4 & 2.3 & .1 & .1 \\
\hline Escape distance (in meters) & 3.0 & 1.9 & .3 & .3 \\
\hline Chase distance (in meters) & 33.5 & 21.7 & .3 & .3 \\
\hline
\end{tabular}

There was no significant difference between groups in the number of lines crossed during the initial 5min period (activity measure) on Day $3[\mathrm{t}(17)=.1$, $\mathrm{p}>.05]$ or on Day 40 [t(17)=.36, p > .05]; both groups showed similar decreases in activity between Day 3 and Day 40. With the exception of one animal, whose data were discarded, no animal displayed aberrant circling or other aberrant movement patterns.

When the human experimenter entered the runway, control animals tended to freeze at the end of the runway furthest from the experimenter. As the experimenter approached, the animal would suddenly turn and flee until the experimenter was not visible. Such flight occurred on $93.4 \%$ of the test trials and was accompanied by vocalization and threatening jumps. In contrast, the experimental rats showed little reaction to the presence of an experimenter. The ongoing activity of the animals was not interrupted, there were no vocalizations, and flight was observed on only $3.3 \%$ of the test trials. This difference in behavior did not disappear over time: On Day 3, the proportion of flight responses was reliably higher for the control group $[U(6,13)=0$, $\mathrm{p}<.001$ ], and the chase distance was also higher in these animals $[U(6,13)=0, p<.001]$. These differences continued to be significant on Postoperative Day 40 [flight proportion, $\mathrm{U}(6,13)=3, \mathrm{p}<.002$; chase distance, $\mathrm{U}(6,13)=0, \mathrm{p}<.001]$. MannWhitney $U$ tests were necessitated for these and certain other measures because requirements for parametric statistics were not met.

Figure 2 presents responses of the experimental and control groups on the following tasks: jump and flinch to dorsal contact, boxing and jump-attack to vibrissae contact, jump-attack to a conspecific.

When control rats were tapped on the back, their startle response was dramatic and immediate. They would vocalize and jump into the air in leaps exceeding $50 \mathrm{~cm}$. When lesioned animals were tapped on the back, their startle response was virtually absent. They did not vocalize or jump, there was rarely more than a flinch of the tapped surface, and frequently there was no reaction at all. The startle scores were significantly lower for the experimental group than for the control group on Day $3[t(17)=14.8]$, Day $10[\mathrm{t}(17)=9.9]$, Day $20[\mathrm{t}(17)=6.33]$, and Day 40 $[t(17)=10.08 ; p<.001$ in each case $]$.
When a brush was used to stimulate the vibrissae, control rats would vocalize and either jump-attack or box on nearly every stroke. Experimental rats tended to avoid stimulation by the vibrissae brush. Boxing and jump-attacks were totally abolished in the experimental rats except for one box response of a single animal on Day $3[\mathrm{U}(6,13)=0, \mathrm{p}<.001$ for all test days].

When the control animals were confronted with an anesthetized conspecific, they vocalized, jumpattacked, and bit. The experimental animals showed little or no reaction to the anesthetized conspecific, showing no jump-attacks or vocalization. While some boxing was seen on Day 3 and on Day 40 in two experimental animals, it was much less than that of the control animals. Defensive reactions to a conspecific were virtually abolished on all test days $[\mathrm{U}(6,13)=0$, $\mathrm{p}<.001$ for all comparisons].

\section{Handling Tests}

Figure 3 presents the data for reactions to handling. At no time could the experimenter's hand approach a control animal without eliciting vocalization and biting. In fact, these animals could not be picked up due to intense struggling and biting at the experimenter's gloved hand. In contrast, experimental animals were easily handled. Many of the experimental animals would groom while being held and could be picked up without the use of gloves. Ratings of defensiveness

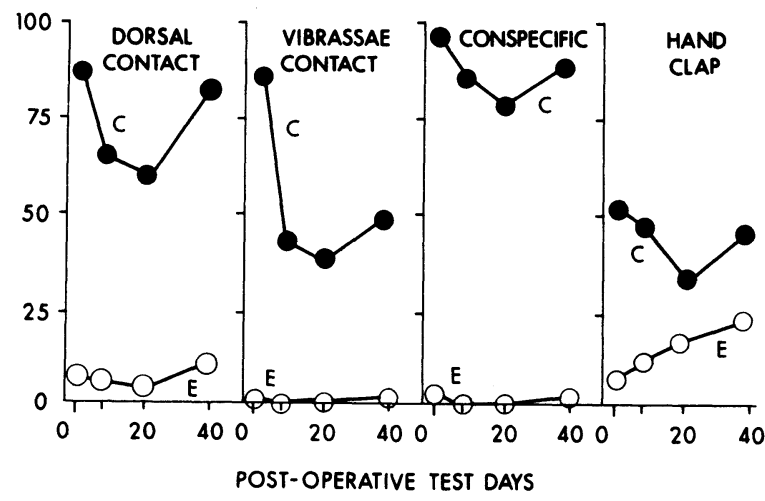

Figure 2. Percentage of maximum weighted startle score to dorsal tapping, of trials on which boxing or jump-attack to vibrissae contact occurred, percentage of trials on which jump-attack to a conspecific occurred, and percentage of maximum weighted startle score for a hand clap for wild rats with central gray lesions (E) and for controls (C). 


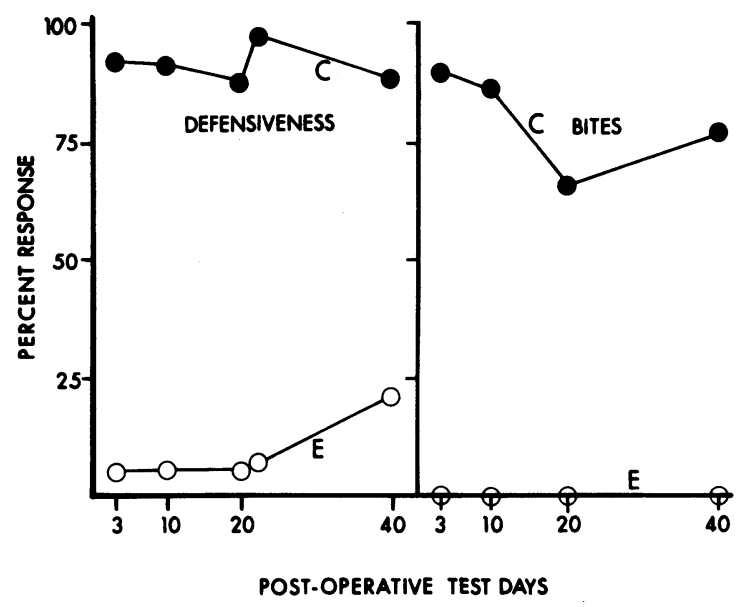

Figure 3. Defensiveness to handling as a proportion of the maximum possible defensiveness score (3.0), and percentages of bites to handling for experimental and control rats.

to handling were significantly different for the two groups on all test days $[\mathrm{U}(6,13)=0, \mathrm{p}<.001$ for all comparisons].

\section{Shock-Elicited Defense}

Table 2 presents results of the shock tests. The threshold for eliciting a jump response was not significantly different for the two groups $[t(17)=.33$, $p>.05]$. However, when placed in the shockbox with a conspecific, control animals tended to freeze or box, while experimental animals in the same situation did not. This difference in behavior was significant $[U(6,13)=0, p<.001]$.

Shock onset elicited jumping and vocalization for both experimental and control groups. Control animals directed jump-attacks at the conspecific and frequently bit this animal on the snout, while the experimental group did not jump-attack or bite $[U(6,13)$ $=0, p<.001]$. Only one of the experimental animals showed any boxing, while the remaining experimental animals showed only jumping in response to shock.

This pattern of differences was obtained with intershock intervals of $10 \mathrm{sec}$. When shock was given at 2-sec intervals, control subjects boxed on the average after 2 shocks, while the experimental rats boxed briefly after 9 shocks $[t(17)=2.29, p<.001]$. All but two animals showed some boxing before the limit of 20 shocks was reached. The two animals that did not box had extensive damage to the ventral areas of the central gray.

Immediately after being tested for shock-elicited defense, all subjects were again tested for defense elicited by tactile stimulation. When approached by the experimenter's gloved hand, the control rats vocalized and bit. All control animals bit when being picked up, while none of the experimentals bit or vocalized when they were picked up. The control rats were again rated as significantly more defensive than the experimental animals $[\mathrm{U}(6,13)=0, \mathrm{p}<.001]$.

\section{Defensive Attack Behavior}

Before shock was given in the tube-test procedure, control rats vocalized to the conspecific and also showed high levels of biting attack. In contrast, the experimental rats did not vocalize or bite. The difference in vocalization $[U(6,13)=0, p<.001]$ and in the number $[t(17)=5.59, \mathrm{p}<.001]$ and frequency $[\mathrm{U}(6,13)=3.5, \mathrm{p}<.002]$ of bites on the anesthetized conspecific during this period were highly significant. When shocks were given, vocalization $[\mathrm{U}(6,13)=5, \mathrm{p}<.002]$, number $[\mathrm{t}(17)=3.19$, $\mathrm{p}<.01]$, and frequency of bites $[\mathrm{U}(6,13)=6, \mathrm{p}<$ .02] were reliably lower in the experimental rats. It should be noted that 11 of the 13 experimental animals did show some vocalization and biting following shock in this procedure.

\section{Discussion}

These data clearly indicate that damage to lateral central gray reduced or eliminated fear responses to a variety of stimuli. These deficits appeared to be fairly permanent, with no change in responsiveness over $\mathbf{4 0}$ days of repeated testing.

The changes in defensive behavior after central gray damage also appear to be relatively specific, in that activity levels and shock thresholds were not altered in the experimental rats and there was no evidence of significant motoric impairment. Finally, in view of the finding that all but two of the experimental animals showed some boxing, biting, etc., in a reflexive fighting situation and the tube test

Table 2

Shock-Elicited Defensive and Pain-Induced Defensive Aggression Behaviors of Rats With Central Gray Damage and Operated Controls

\begin{tabular}{lrr} 
& \multicolumn{2}{c}{ Group } \\
\cline { 2 - 3 } \multicolumn{1}{c}{ Response Measure } & \multicolumn{2}{c}{ Central } \\
\multicolumn{1}{c}{ Reflexive Fighting Test (22 Days Post-Op) } \\
C & Gray \\
\hline Jump threshold (in milliamperes) & .35 & .36 \\
Percent of trials with boxing before shock & 22 & 0 \\
Percent of trials with boxing to shock & 60 & 0 \\
Percent of trials with jump-attacks to shock & 53 & 0 \\
Number of bites & 1 & 0 \\
Number of shocks to box & 2 & 9 \\
$\quad$ Defensive Biting Tube Test (28 Days Post-Op) & \\
Before Shock & & \\
Percent of subjects vocalizing to target & 83 & 0 \\
Percent of subjects biting target & 83 & 31 \\
Number of bites & 14 & 1.5 \\
Shock & & \\
Percent of subjects vocalizing to target & 100 & 60 \\
Percent of subjects biting target & 100 & 66 \\
Number of bites in 10 trials & 39.0 & 18.4 \\
\hline
\end{tabular}


when shocks were given at 2-sec intervals, it seems clear that reduced defensiveness to nonpainful stimuli and to shock given at longer intervals cannot be attributed to an inability to perform the motor acts involved.

This analysis suggests that the deficit of the experimental animals may reflect either a sensory/perceptual deficit in the discrimination or recognition of threat stimuli or altered associative or motivational aspects of responsivity to threat stimuli, as suggested by Adams (1979).

One problem in clarifying the mechanism involved is that all experimental rats had major damage to the superior colliculus, which has been shown to have extensive connections with visual and tactile systems. Experiment 2 was an attempt to assess the possibility that collicular damage was involved in the pattern of deficits shown by the experimental animals of Experiment 1.

\section{EXPERIMENT 2}

The superior colliculus is involved in the control of eye movements (Stein, Goldberg, \& Clamann, 1976) and visually guided behavior in the cat (Sprague, Berlucci, \& DiBernardino, 1970) and rat (Pope \& Dean, 1979; Weldon \& Smith, 1979). Cells in this area also respond to tactile (Nagata \& Kruger, 1979) and noxious stimuli (Stein \& Dixon, 1978). Stein, Magalhaes-Castro, and Kruger (1976) have shown that both visual and tactile elements in the superior colliculus play a role in stimulus-oriented behavior. Finally, the superior colliculus has been shown to have reciprocal connections with the central gray (Graham, 1977; Grofova, Ottersen, \& Rinvik, 1978; Edwards, 1977). These findings suggest that damage to the superior colliculus occasioned by the central gray lesions of Experiment 1 may have been a factor in the finding of defense deficits to visual and tactile stimuli in experimental animals. Experiment 2 evaluated this possibility through analysis of the effects of lesions in the superior colliculi.

\section{Method}

\section{Subjects}

The subjects were 12 female $R$. norvegicus trapped 4 to 8 months before testing in the cane fields of Hilo, Hawaii. These animals weighed from 130 to $240 \mathrm{~g}$ at the time of surgery, and were housed individually with free access to food and water. Because pilot work indicated no pre- and postoperative differences of wild rats after control surgery, the subjects were used as their own controls.

\section{Procedure}

Surgical procedures were the same as in Experiment 1. All animals had bilateral lesions $(2 \mathrm{~mA}, 10 \mathrm{sec})$ placed in the posterior superior colliculus at $-5.5 \mathrm{~mm}$ posterior to bregma, $\mathrm{ML} \pm 1$, and $4.0 \mathrm{~mm}$ below the dura.

Behavioral procedures were those used in Experiment 1, except that the shock-elicited defense procedure and the defensive attack procedure were omitted. All subjects were tested 1 day preoperatively and again 3 days postoperatively.

\section{Results}

\section{Histological Results}

Seven animals were eliminated from statistical analysis because of lack of bilateral damage to the superior colliculus or because of bilateral damage to the central gray. Five animals were used in the statistical evaluation. Figure 4 shows representative lesions. All animals had complete destruction of the superficial layers of the superior colliculus. The amount of destruction in the deep layers varied from $75 \%$ to $100 \%$.

\section{Behavioral Results}

Table 3 presents results of the behavioral tests. Superior colliculus-damaged animals showed no changes in activity $[\mathrm{t}(4)=.43, \mathrm{p}<.05]$. When approached, the subjects did not orient toward the experimenter. Only when the experimenter was very close or when he touched the subject did the rat orient towards the experimenter. There was a significant reduction in the distance which elicited flight $[\mathrm{t}(14)=2.74, \mathrm{p}<.025]$. However, animals showed normal flight following contact, with no reduction in the escape distance $[t(4)=.42]$.

Subjects with damage to the superior colliculi showed a significant decrease in reactivity to dorsal stimulation $[\mathrm{t}(4)=2.6, \mathrm{p}<.05]$ and to stimulation of the vibrissae $[t(4)=2.41, p<.05$ ], but defensive

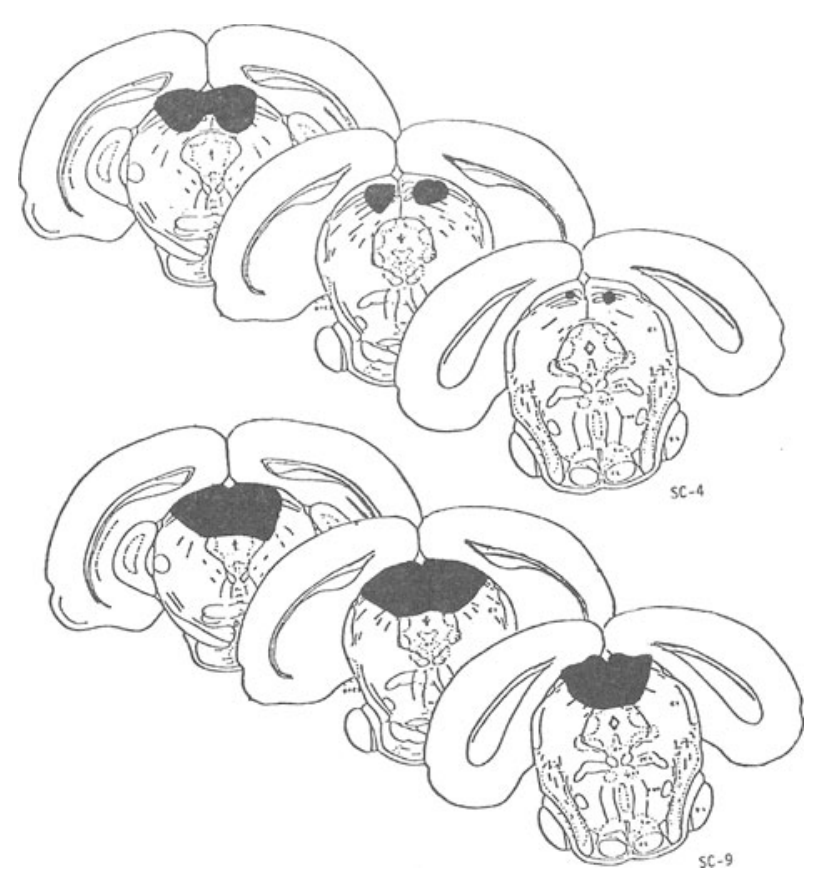

Figure 4. Animals with maximal and minimal extent of lesions in the superior colliculus. 
Table 3

Behavioral Responses of Rats with Superior Colliculus Lesions

\begin{tabular}{lrrr}
\hline & Pre-Op & Post-Op & \multicolumn{1}{c}{ C } \\
\hline Lines crossed in 5 min & 46.4 & 32.0 & 63.5 \\
Percent of trials, avoiding & 92.0 & 36.0 & 86.7 \\
Percent of trials, contacting & 8.0 & 64.0 & 13.3 \\
Mean avoidance distance (in meters) & 2.1 & .4 & 2.4 \\
Mean escape distance & 1.9 & 1.7 & 2.5 \\
Mean chase distance & 21.0 & 11.6 & 33.5 \\
Mean reaction to dorsal contact & 4.3 & 2.8 & 3.4 \\
Percent trial biting conspecific & 100 & 66.7 & 100 \\
Mean reaction to hand clap & 3.4 & 1.6 & 2.5 \\
Rated defensiveness & 3.0 & 2.8 & 2.8 \\
\hline
\end{tabular}

Note $-C=$ control .

reactions to an anesthetized conspecific were unchanged. There was also no change in the frequency of boxing $[\mathrm{t}(4)=1.06, \mathrm{p}>.05]$, biting $[\mathrm{t}(4)=.45$, $p>.05]$, jump-attacks [t(4) $=.46, p>.05]$, or vocalization $[t(4)=1.91, p>.05]$.

No subject could be picked up. Any approach with a gloved hand elicited vocalization and biting. All subjects were rated as very defensive, with no change from the pretest $[t(4)=.67, p>.05]$.

\section{Discussion}

Animals with extensive destruction of the superior colliculus had deficits in visually guided behavior and showed decreased responsivity to some visual and tactile stimuli, with a significant reduction in the distance that elicited flight. However, the escape distance was not significantly altered, nor were reactions to handling or other measures of defensive attack. This suggests that the animals were deficient in recognition of specific types of stimuli, but did not exhibit a general pattern of reduced defensiveness such as was shown by the experimental rats of Experiment 1 . This, in turn, strongly suggests that central gray damage in that study was responsible for the pattern of the changes observed.

This pattern included profound decreases in a wide variety of measures of fearfulness. Animals were less responsive to painful and nonpainful stimuli, with the latter visual and tactile stimulus modes. Conspecific and nonconspecific (human) threat stimuli were both less effective in eliciting signs of fear.

This finding of reduced reactivity to nonpainful threat stimuli is particularly interesting in terms of the large body of research linking central gray mechanisms to alterations of pain thresholds (cf. Hasobuchi, Adams, \& Linchitz, 1977). The present results concur with such findings, but suggest that the central gray is an essential component of a more inclusive brain mechanism, one which regulates defensive behaviors to nonpainful as well as noxious threat stimuli. As such, it invites comparison with other areas, notably the amygdala, in which taming may be pro- duced by lesions. The behaviors associated with the amygdala-lesion syndrome include sharply reduced reactivity to handling or other nonpainful stimuli in wild rats (Woods, 1956), but less reduction in defensiveness when painful stimuli are involved (Blanchard \& Blanchard, 1972).

Recent attempts to localize the specific site of this amygdala-lesion effect suggest that only the central nucleus of the amygdala is involved (Werka, Skar, \& Ursin, 1978), although Blanchard, Blanchard, Lee, and Williams (in press) have obtained a comparable behavior change in wild rats after lesions restricted to the striatum.

Both nucleus centralis and the striatum are notable for their direct and massive connections to the midbrain (Bunney \& Aghajanian, 1976; McGeer, Eccles, \& McGeer, 1978). Taken together with these earlier results, the present findings may begin to suggest the outline of a telencephalic-mesencephalic system underlying defensive behaviors. In this system, higher portions are primarily involved in the elaboration of defensiveness to more complex nonpainful stimuli, while lower (midbrain) elements underlie reactivity to painful stimuli as well.

\section{REFERENCES}

Adnms, D. B. The activity of single cells in the midbrain and hypothalamus of the cat during affective defense behavior. Archives Italiennes de Biologie, 1968, 106, 243-269.

ADAms, D. B. Brain mechanisms for offense, defense, and submission. The Behavioral and Brain Sciences, 1979, 2, 201-241.

Baxter, B. L. Comparison of the behavioral effects of electrical or chemical stimulation applied at the same brain loci. Experimental Neurology, 1967, 19, 412-432.

Blanchard, D. C., \& Blanchard, R. J. Innate and conditioned reactions to threat in rats with amygdaloid lesions. Journal of Comparative and Physiological Psychology, 1972, 81, 281-290.

Blanchard, D. C., Blanchard, R. J., Lee, E. M. C., \& Williams, G. Taming in the wild Norway rat following lesions in the basal ganglia. Physiology \& Behavior, in press.

Bunney, B. S., \& Aghajanian, G. K. The precise localization of nigral afferents in the rat as determined by a retrograde tracing technique. Brain Research, 1976, 117, 423-435.

Edwards, M. A., \& Adams, D. B. Role of midbrain central gray in pain-induced defensive boxing of rats. Physiology \& Behavior, 1974, 13, 113-121.

EDwards, S. B. The commissural projection of the superior colliculus in the cat. Journal of Comparative Neurology, 1977, 173, 23-40.

GrAHAM, J. An autoradiographic study of the efferent connections of the superior colliculus in the cat. Journal of Comparative Neurology, 1977, 173, 629-654.

Grofova, I., Ottersen, O. P., \& Rinvik, E. Mesencephalic and diencephalic afferents to the superior colliculus and periaqueductal gray substance demonstrated by retrograde axonal transport of horseradish peroxidase in the cat. Brain Research, 1978, 146, 205-220.

HAlPERN, M. Effects of midbrain central gray matter lesions on escape-avoidance behavior in rats. Physiology \& Behavior, 1968, 3, 171-178.

Hasobuchi, Y., Adams, J. E., \& Linchitz, R. Pain relief by electrical stimulation of the central gray matter in human and its reversal by naloxone. Science, 1977, 197, 183-186. 
Liebman, J. M., Mayer, D. J., \& Liebeskind, J. C. Mesencephalic central gray lesions and fear-motivated behaviors in rats. Brain Research, 1970, 23, 353-370.

McGeer, P. L., Eccles, J. C., \& McGeer, E. G. Molecular neurobiology of the mammalian brain. New York: Plenum Press, 1978.

Nagata, T., \& Kruger, L. Tactile neurons of the superior colliculus of the cat: Input and physiological properties. Brain Research, 1979, 174, 19-37.

Nashold, B. S., Wilson, W. P., \& Slaughter, D. G. Sensations evoked by stimulation in the midbrain of man. Journal of Neurosurgery, 1969, 30, 14-24.

Pope, S. G., \& DeAn, P. Hyperactivity, aphagia and motor disturbance following lesions of superior colliculus and underlying tegmentum in rats. Behavioral and Neural Biology, 1979, 27, 433-453.

Sandner, G., Schmitt, P., \& Kardi, P. Central gray and medial hypothalamic stimulation: Correlation between escape behavior and unit activity. Brain Research, 1979, 170, 459-474.

Skultety, F. M. The behavioral effects of destructive lesions of the periaqueductal gray matter in adult cats. Journal of Comparative Neurology, 1958, 110, 337-362.

Sprague, J. M., Berlucci, G., \& DiBernardino, A. The superior colliculus and pretectum in visually guided behavior and visual discrimination in the cat. Brain Behavior, 1970, 3, 285-294.
Stein, B. E., \& Dixon, J. P. Superior colliculus cells respond to noxious stimuli. Brain Research, 1978, 158, 65-73.

Stein, B. E., Goldberg, S. J., \& Clamann, H. P. The control of eye movements by the superior colliculus in the alert cat. Brain Research, 1976, 118, 469-474.

Stein, B. E., Magalhaes-Castro, B., \& Kruger, L. Relationship between visual and tactile representations in cat superior colliculus. Journal of Neurophysiology, 1976, 39, 401-419.

VAlenstein, E. S. Independence of approach and escape reactions to electrical stimulation of the brain. Journal of Comparative and Physiological Psychology, 1965, 60, 20-30.

Weldon, D. A., \& Smith, C. J. Superior colliculus lesions and environmental experience: Nonvisual effects on problem solving and locomotor activity. Physiology \& Behavior, 1979, 23, 159-165.

Werka, T., Skar, J., \& Ursin, H. Exploration and avoidance in rats with lesions in amygdala and piriform cortex. Journal of Comparative and Physiological Psychology, 1978, 92, 672-681.

Woods, J. W. 'Taming' of the wild Norway rat by rhinencephalic lesions. Nature, 1956, 869, 4538.

(Received for publication March 31, 1981; revision accepted May 6, 1981.) 